\title{
Progressive blindness in a child with neurofibromatosis type 1
}

\author{
V P Sinhabahu, D S Wijesekara
}

Ceylon Medical Journal 2014; 59: 150

A-13 years old boy presented with progressive visual loss of 7 years duration. He had difficulty in seeing objects at a distance at 6 years of age. The visual loss progressed and at presentation he was able to perceive only bright light. He had neurofibromatosis $1(\mathrm{NF}-1)$, double curve scoliosis and generalised epilepsy. NF-1 was diagnosed as he had multiple $(>6)$ café-au lait spots, palpable neurofibromas and a first degree relative with NF - 1, a sister [1]. He was treated with sodium valproate and clobazam for epilepsy and a Milwaukee brace for scoliosis. No family history of blindness or visual disorders was present. He was extensively investigated by neuro-logists and ophthalmologists. Repeated fundal photographs and MRI scans of brain had been performed. MRI scan did not reveal any mass lesions or abnormality in the orbit, globe of the eye, optic tract or occipital cortex. Fundoscopy showed bilateral retinitis pigmentosa (RP) with bilateral optic atrophy (Figure). He is followed up in the low vision clinic.
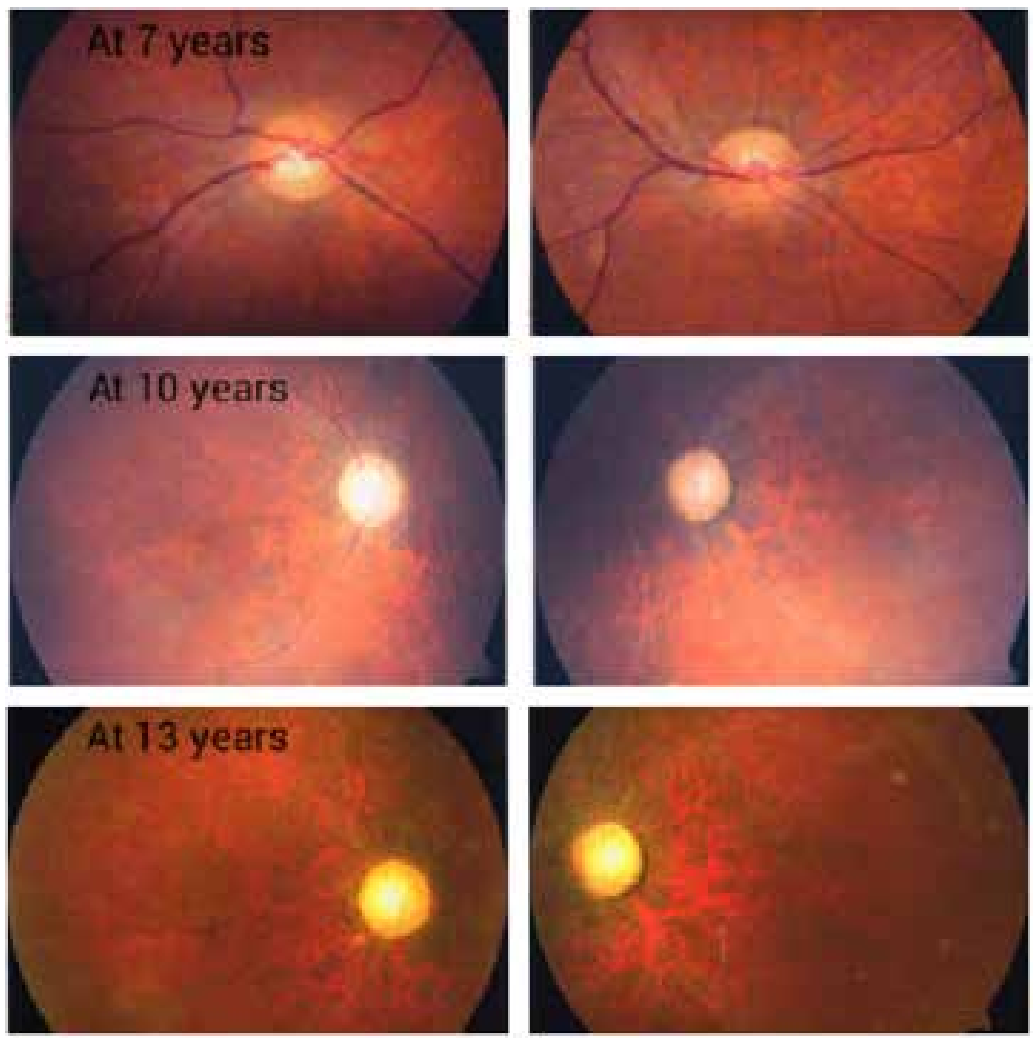

Figure. Serial fundal photographs.
NF-1 is an autosomal dominant disorder. Incidence is 1 in 3000. The phenotype of NF-1 varies substantially [1]. Scoliosis is common in patients with neurofibromatosis [2]. NF-1 predisposes to central nervous system (CNS) tumors. Most of these are pilocytic astrocytomas, the CNS tumours that arise in children and are located in the optic pathways or in the brainstem [3]. CNS tumours can cause optic atrophy due to compression of the optic tract. Repeated MRI scans of the brain excluded the possibility of space occupying lesions or visual pathway lesions in this child. Although retinitis pigmentosa in an adult with NF -1 and opticglioma was reported, retinitis pigmentosa and bilateral optic atrophy without a tumour has not been reported as a cause of blindness in children with NF- 1 [4]. The occurrence of NF-1 and RP, could be a coincidence. However there could be an association between retinitis pigmentosa (RP) and NF-1 leading to blindness.

\section{References}

1. Sahin M. Neurocutaneous Syndromes. In: Kliegman RM, Stanton BF, St. Geme J, Schor N, Behrman RE, eds. Nelston Textbook of Pediatrics. 19th ed. Philadelphia, Saunders Elsevier; 2011.

2. Hresko M T. Idiopathic Scoliosis in Adolescents. New England Journal of Medicine 2013; 368: 834-41.

3. Ganesh S, Gupta A, Sharma M, Bhuttan S. A case of neurofibromatosis 1 presenting with an optic pathway glioma with an early onset and an aggressive course. Indian Journal of Ophthalmology 2008; 56: 161-2.

4. La Piana FG. Sectoral retinal pigmentation in neurofibromatosis Annals of Ophthalmology 1977; 9: 413-22.

Professorial Paediatric Unit, Colombo South Teaching Hospital, Sri Lanka.

Correspondence: VPS, e-mail: <Sinbad.Ik@gmail.com>. Received 15 June 2014 and revised version accepted 16 August 2014. Competing interests: none declared. 